Revised Version 19 August 2005

\title{
Coordination Environment of Aqueous Uranyl(VI) Ion.
}

Michael Bühl,*," Romain Diss, ${ }^{\star}$ and Georges Wipff ${ }^{\ddagger}$

\section{Supporting Information}

\section{Construction and Validation of the Uranium Pseudopotential}

For uranium, a semicore (or small-core) pseudopotential was constructed following the procedure adopted previously for other transition-metal nuclei. ${ }^{1}$ A relativistic atomic reference calculation was performed for the $\left[1 s^{2} 2 s^{2} 2 p^{6} 3 s^{2} 3 p^{6} 3 d^{10} 4 s^{2} 4 p^{6} 4 d^{10} 4 f^{14} 5 s^{2} 5 p^{6} 5 d^{10}\right] 6 s^{2} 6 p^{6} 5 f^{2} 6 d^{1}$ state, and a pseudopotential was created for the core in brackets, using cutoff radii of 1.4, 1.6, 2.4, and 1.3 a.u. for the $s, p, d$, and $f$ channels, respectively. ${ }^{2}$ Since this atomic calculation was performed for a $\mathrm{U}^{3+}$ state, the resulting pseudopotential is thus designed for uranium in high oxidation states.

Initial validation tests were performed for gaseous $\mathrm{UCl}_{6}$ in a $10 \AA$ box. Increasing the wavefunction cutoff beyond 80 Ry resulted only in minor changes of the optimized $\mathrm{U}-\mathrm{Cl}$ distance (on the order of $0.01 \AA$ ). As documented in Table S1, the optimized distance is in good accord with a nonperiodic reference calculation at the BLYP/SDD/6-31G* level (performed with Gaussian $03,{ }^{3}$ employing the relativistic Stuttgart-Dresden effective core potential together with the corresponding [8s7p6d4f] valence basis set ${ }^{4}$ and 6-31G* basis on $\mathrm{U}$ and $\mathrm{Cl}$, respectively). Harmonic frequencies computed with the BLYP/CP-opt and BLYP/SDD/6-31G* procedures agreed to within $15 \mathrm{~cm}^{-1}$.

Table S1: Optimized and observed U-Cl ond distanes $r$ [in $\AA$ ] for $\mathrm{UCl}_{6}\left(O_{h}\right.$ symmetry)

Level $\quad r(\mathrm{U}-\mathrm{Cl}) \quad$ Reference

\begin{tabular}{llc}
\hline Dirac-Fock & 2.46 & 5 \\
HF/SDD/6-31G* & 2.451 & this work \\
BLYP/SDD/6-31G* & 2.506 & $"$ \\
BLYP/CP-opt & 2.494 & $"$ \\
Experiment & $2.46(1)$ & 6 \\
\hline
\end{tabular}

\# Max-Planck-Institut für Kohlenforschung, E-mail: buehl@mpi-muelheim.mpg.de Laboratoire MSM, E-Mail wipff@chimie.u-strasbg.fr 
Chart S1

Additional validation studies were performed for gaseous and aqueous $\left[\mathrm{UO}_{2} \mathrm{Cl}_{4}\right]^{2-}$ (Chart $\left.\mathrm{S} 1\right)$ in a slightly larger box (11.5 $\AA$ ). The same parameters as detailed in the main paper were employed. For CPMD simulations in water, pre-equilibrated coordinates from a study of aqueous $\left[\mathrm{Fe}(\mathrm{CN})_{5}(\mathrm{NO})\right]^{2-}$ were taken as starting point, ${ }^{7}$ manually replacing the cyanoferrate with the uranyl complex. With 45 water molecules in the box, the density of the resulting solution, 1.315, corresponds to that of typical uranyl complexes (e.g. uranyl nitrate) with the same concentration, 34 weight- $\%{ }^{8}$ The system was heated up instantaneously with the single Nosé-Hoover thermostat (frequency 1800 $\mathrm{cm}^{-1}$ ), and the first $0.5 \mathrm{ps}$ were taken as equilibration.

Table S2: Bond distances [in $\AA$ ] gaseous and aqueous $\left[\mathrm{UO}_{2} \mathrm{Cl}_{4}\right]^{2-}$ (BLYP functional; in parentheses: standard deviation).

phase level $\quad r(\mathrm{U}=\mathrm{O}) \quad r(\mathrm{U}-\mathrm{Cl})$

\begin{tabular}{llll}
\hline gaseous & SDD/6-31G* & 1.820 & 2.735 \\
& CP-opt & 1.816 & 2.720 \\
& CPMD & $1.819(15)$ & $2.758(81)$ \\
& & & \\
aqueous & $\mathrm{CPMD}$ & $1.824(35)$ & $2.709(75)$ \\
& Experiment & \\
& & 1.76 & 2.67 \\
solid & Experiment $^{b}$ & $1.72-1.78$ & $2.63-2.69$ \\
& & & \\
\hline
\end{tabular}

${ }^{a}$ EXAFS, reference 9. ${ }^{b} \mathrm{X}$-Ray, reference 10.

Again, the CP-opt parameters agree well with the nonperiodic gas-phase reference data (compare CP-opt and SDD/6-31G* in Table S2). The CPMD simulations, which remained stable at all times, were performed for 1.5 and $2.5 \mathrm{ps}$ in vасио and in water, respectively. As expected, the mean bond distances at $300 \mathrm{~K}$ in the gas phase are elongated with respect to the equilibrium values (compare gaseous CP-opt and CPMD data in Table S2), due to the anharmonicity of the stretching potentials. On going from the vapor into the aqueous phase, a further, slight elongation is found for the $\mathrm{U}=\mathrm{O}$ 
bonds, whereas a significant bond contraction, ca. $0.05 \AA$, is obtained for the U-Cl bonds. The geometrical parameters emerging from the CPMD simulation in water are in reasonable agreement with experimental data in the solid or in solution (Table S2), and show the extent of overestimation of bond distances between heavier elements typical for the gradient-corrected density functional employed. $^{11}$

Further validation studies for uranyl complexes with other ligands, in particular chelating diamides, confirms the consistency of the CP-opt data with other relativistic DFT methods, also as far as relative energies of isomeric complexes are concerned. Detailed results of these studies will be published separately. In short, the pseudopotential for uranium constructed for the use in CPMD simulations has proven to furnish reliable results and should be a versatile ingredient for such studies of uranyl(VI) complexes.

\section{Further Details for Uranyl Hydrates}

The same setup as for the $\left[\mathrm{UO}_{2} \mathrm{Cl}_{4}\right]^{2-}$ simulations described above has been used for the gaseous and aqueous $\left[\mathrm{UO}_{2}\left(\mathrm{OH}_{2}\right)_{5}\right]^{2+}$ species, save for a larger box size (13.0 ̊). With this lattice parameter, the smallest intermolecular distance between two complexes in adjacent boxes is ca. $6.2 \AA$ in the case of $\mathbf{3}$. For the simulation in aqueous phase, the number of water molecules was chosen such as to render a density of 1 , mimicking a diluted solution. No electrostatic decoupling between replicated cells was included, as it had been shown that no noticeable errors are introduced by this procedure in the case of divalent ions. ${ }^{12,7}$ Optimized coordinates of complexes $\mathbf{1}-\mathbf{3}$ in the gas phase are collected in the Appendix below.

Convergence of quantities extracted from MD simulations is always an issue of concern. In context with the pointwise thermodynamic integration scheme, the precision of the mean constraint force $\langle f(r)\rangle$ is of particular interest. The convergence of this parameter is illustrated for a typical CPMD run in Figure S1. While the actual forces $f$ oscillate strongly, the average over all values (bold red line in Figure S1) appears to be well converged already ca. 0.5 ps after start of data sampling (at 0.5 ps), and shows no significant drift for another picosecond. In the particular example depicted in Figure S1, the final value for $\langle f(r)\rangle$ is $0.01097 \mathrm{au}$, with a standard deviation of 0.0003 au during the last picosecond. Occasionally, sampling over somewhat longer times was necessary for a comparable convergence, and the maximum standard deviation of any $\langle f(r)\rangle$ value was $0.0007 \mathrm{au}$. 


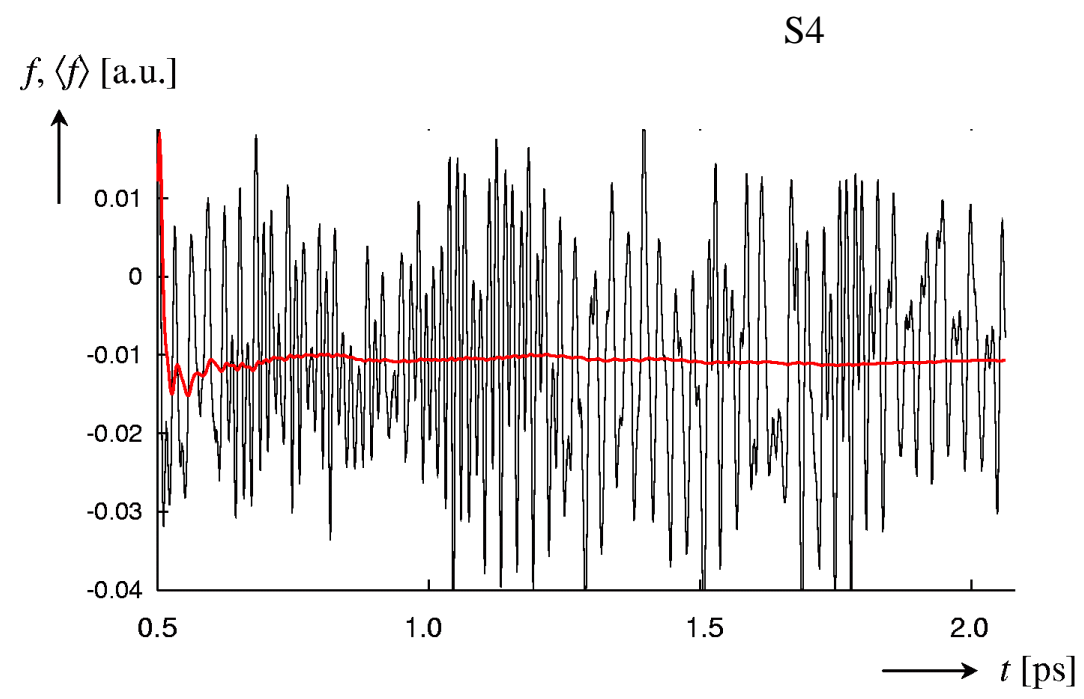

Figure S1: Convergence of the mean constraint force $\langle f\rangle$ (bold red line), obtained as the running (cumulative) average over the instantaneous forces $f$ (normal black line) from one CPMD run in water with fixed $r=2.95 \AA$ ).

\section{References}

(1) For instance, for Mn: (a) Bühl, M. J. Phys. Chem. A. 2002, 106, 10505; for Co: (b) Grigoleit, S.; Bühl, M. J. Chem. Theory Comput. 2005, 1, 181.

(2) Using a program by D. R. Hamann based on the following references: (a) Hamann, D. R. Phys. Rev. B. 1989, 40, 2980; (b) Bachelet, G. B.; Hamann, D. R.; Schlüter, M. Phys. Rev. B 1982, 26, 4199; (c) Hamann, D. R.; Schlüter, M.; Chiang, C. Phys. Rev. Lett. 1979, 43, 1494.

(3) M. J. Frisch, G. W. Trucks, H. B. Schlegel, G. E. Scuseria, M. A. Robb, J. R. Cheeseman, J. A. Montgomery, Jr., T. Vreven, K. N. Kudin, J. C. Burant, J. M. Millam, S. S. Iyengar, J. Tomasi, V. Barone, B. Mennucci, M. Cossi, G. Scalmani, N. Rega, G. A. Petersson, H. Nakatsuji, M. Hada, M. Ehara, K. Toyota, R. Fukuda, J. Hasegawa, M. Ishida, T. Nakajima, Y. Honda, O. Kitao, H. Nakai, M. Klene, X. Li, J. E. Knox, H. P. Hratchian, J. B. Cross, C. Adamo, J. Jaramillo, R. Gomperts, R. E. Stratmann, O. Yazyev, A. J. Austin, R. Cammi, C. Pomelli, J. W. Ochterski, P. Y. Ayala, K. Morokuma, G. A. Voth, P. Salvador, J. J. Dannenberg, V. G. Zakrzewski, S. Dapprich, A. D. Daniels, M. C. Strain, O. Farkas, D. K. Malick, A. D. Rabuck, K. Raghavachari, J. B. Foresman, J. V. Ortiz, Q. Cui, A. G. Baboul, S. Clifford, J. Cioslowski, B. B. Stefanov, G. Liu, A. Liashenko, P. Piskorz, I. Komaromi, R. L. Martin, D. J. Fox, T. Keith, M. A. Al-Laham, C. Y. Peng, A. Nanayakkara, M. Challacombe, P. M. W. Gill, B. Johnson, W. Chen, M. W. Wong, C. Gonzalez, and J. A. Pople, Gaussian 03, Gaussian, Inc., Pittsburgh PA, 2003.

(4) Küchle, W.; Dolg, M.; Stoll, H.; Preuss, H. J. Chem. Phys. 1994, 100, 7535.

(5) Malli, G. L. Mol. Phys. 2003, 101, 287. 
(6) Gas-phase electron diffraction: Ezhov, Y. S.; Komarov, S. A.; Sevastyanov, V. G.;

Bazhanov, V. I. J. Struct. Chem. 1993, 34, 473.

(7) M. Bühl, F. T. Mauschick, Phys. Chem. Chem. Phys. 2002, 4, 5508.

(8) E.g.: Lax, E. (Ed.) D’Ans-Lax Taschenbuch für Chemiker und Physiker, 3rd Ed., Vol. 1, Springer Verlag, Berlin 1967.

(9) Formed in Dowex resin with high effective $\mathrm{Cl}^{-}$concntration, with an average chloride coordination number of 4.2: Allen, P. G.; Bucher, J. J.; Shuh, D. K.; Edelstein, N. M.; Reich, T. Inorg. Chem. 1997, 36, 4676.

(10) The $\left[\mathrm{UO}_{2} \mathrm{Cl}_{4}\right]^{2-}$ ion is part of numerous single crystals characterized by X-ray crystallography; the given "extreme" values are taken from: (a) di Spio, L.; Tondello, E.; Pellizzi, G.; Ingletto, G.; Montenero,A. Cryst. Struct. Commun. 1974, 3, $297\left(\mathrm{NMe}_{4}{ }^{+}\right.$couterion); (b) Evans, D. J.; Junk, P. C.; Smith, M. K. New J. Chem. 2002, 26, 1043 (with a quaternary aza-crown ether and two crystal waters; (c) Rogers, R. D.; Bond, A. H. Hipple, W. G. J. Crystallog. Spectrosc. Res. 1990, 20, $611\left\{\left[\mathrm{Ca}\left(15 \text {-crown-5) }\left(\mathrm{H}_{2} \mathrm{O}\right)_{3}\right]^{2+}\right.\right.$ counterion $\}$.

(11) See, e.g.: W. Koch, M. C. Holthausen, A Chemist's Guide to Density Functional Theory, Wiley-VCH, Weinheim, 2000.

(12) Marx, D.; Hutter, J.; Parrinello, M. Chem. Phys. Lett. 1995, 241, 457.

Appendix: BLYP/CP-opt coordinates of complexes $\mathbf{1}-\mathbf{3}$ in the gas phase.

\begin{tabular}{|c|c|c|c|c|c|}
\hline \multirow{2}{*}{$\begin{array}{l}\text { Center } \\
\text { Number }\end{array}$} & \multirow{2}{*}{$\begin{array}{l}\text { Atomic } \\
\text { Number }\end{array}$} & \multirow{2}{*}{$\begin{array}{c}\text { Atomic } \\
\text { Type }\end{array}$} & \multicolumn{3}{|c|}{ Coordinates (Angstroms) } \\
\hline & & & $\mathrm{X}$ & $\mathrm{Y}$ & $\mathrm{Z}$ \\
\hline 1 & 92 & 0 & 0.000574 & 0.000001 & 0.000003 \\
\hline 2 & 8 & 0 & 0.020960 & 0.020833 & 1.780098 \\
\hline 3 & 8 & 0 & 0.020958 & -0.020835 & -1.780096 \\
\hline 4 & 8 & 0 & -2.520324 & 0.000718 & -0.000012 \\
\hline 5 & 8 & 0 & -0.779681 & 2.373658 & -0.003941 \\
\hline 6 & 8 & 0 & -0.781085 & -2.373195 & 0.003934 \\
\hline 7 & 8 & 0 & 2.023801 & 1.457303 & -0.016555 \\
\hline 8 & 8 & 0 & 2.022927 & -1.458505 & 0.016544 \\
\hline 9 & 1 & 0 & -3.102412 & 0.162496 & 0.772719 \\
\hline 10 & 1 & 0 & -3.102499 & -0.160673 & -0.772756 \\
\hline 11 & 1 & 0 & -0.830175 & 2.969196 & 0.774081 \\
\hline 12 & 1 & 0 & -1.099099 & 2.882646 & -0.779507 \\
\hline 13 & 1 & 0 & -1.100822 & -2.881990 & 0.779491 \\
\hline 14 & 1 & 0 & -0.831919 & -2.968701 & -0.774091 \\
\hline 15 & 1 & 0 & 2.559164 & 1.709401 & 0.766159 \\
\hline 16 & 1 & 0 & 2.418731 & 1.906968 & -0.794420 \\
\hline 17 & 1 & 0 & 2.417607 & -1.908393 & 0.794407 \\
\hline 18 & 1 & 0 & 2.558151 & -1.710897 & -0.766172 \\
\hline
\end{tabular}




\section{S6}

2

\begin{tabular}{|c|c|c|c|c|c|}
\hline \multirow{2}{*}{$\begin{array}{l}\text { Center } \\
\text { Number }\end{array}$} & \multirow{2}{*}{$\begin{array}{l}\text { Atomic } \\
\text { Number }\end{array}$} & \multirow{2}{*}{$\begin{array}{c}\text { Atomic } \\
\text { Type }\end{array}$} & \multicolumn{3}{|c|}{ Coordinates (Angstroms) } \\
\hline & & & $\mathrm{X}$ & $\mathrm{Y}$ & $\mathrm{Z}$ \\
\hline 1 & 92 & 0 & 0.035473 & -0.001051 & -0.001729 \\
\hline 2 & 8 & 0 & 0.103120 & -0.005462 & 1.780680 \\
\hline 3 & 8 & 0 & 0.163422 & -0.006062 & -1.781336 \\
\hline 4 & 8 & 0 & -0.791278 & -2.292297 & -0.510239 \\
\hline 5 & 8 & 0 & -2.391098 & -0.173407 & 0.730017 \\
\hline 6 & 8 & 0 & 2.094868 & -1.358023 & 0.153448 \\
\hline 7 & 8 & 0 & -1.185764 & 2.097112 & -0.589208 \\
\hline 8 & 8 & 0 & 1.761423 & 1.754171 & 0.229858 \\
\hline 9 & 1 & 0 & -1.160051 & -2.979396 & 0.084437 \\
\hline 10 & 1 & 0 & -0.817881 & -2.652719 & -1.422984 \\
\hline 11 & 1 & 0 & -3.228736 & -0.264125 & 0.228477 \\
\hline 12 & 1 & 0 & -2.617380 & -0.224411 & 1.683037 \\
\hline 13 & 1 & 0 & 2.621802 & -1.734078 & -0.584085 \\
\hline 14 & 1 & 0 & 2.545491 & -1.604509 & 0.990330 \\
\hline 15 & 1 & 0 & -1.692105 & 2.718658 & -0.024746 \\
\hline 16 & 1 & 0 & -1.297577 & 2.391488 & -1.518746 \\
\hline 17 & 1 & 0 & 2.215558 & 2.267123 & -0.472814 \\
\hline 18 & 1 & 0 & 2.129840 & 2.050361 & 1.090418 \\
\hline
\end{tabular}

3

\begin{tabular}{|c|c|c|c|c|c|}
\hline \multirow{2}{*}{$\begin{array}{l}\text { Center } \\
\text { Number }\end{array}$} & \multirow{2}{*}{$\begin{array}{l}\text { Atomic } \\
\text { Number }\end{array}$} & \multirow{2}{*}{$\begin{array}{l}\text { Atomic } \\
\text { Type }\end{array}$} & \multicolumn{3}{|c|}{ Coordinates (Angstroms) } \\
\hline & & & $\mathrm{x}$ & $\mathrm{Y}$ & Z \\
\hline 1 & 92 & 0 & -0.269124 & -0.000431 & 0.037241 \\
\hline 2 & 8 & 0 & -0.866603 & 0.013881 & 1.716357 \\
\hline 3 & 8 & 0 & 0.297655 & -0.011597 & -1.650905 \\
\hline 4 & 8 & 0 & -0.217405 & 2.450548 & 0.048519 \\
\hline 5 & 8 & 0 & 1.953241 & -0.121191 & 0.813565 \\
\hline 6 & 8 & 0 & -2.587976 & 0.118675 & -0.758773 \\
\hline 7 & 8 & 0 & 4.115907 & -0.000940 & -0.500727 \\
\hline 8 & 8 & 0 & -0.449338 & -2.443654 & -0.004468 \\
\hline 9 & 1 & 0 & -0.437984 & 3.032769 & 0.808485 \\
\hline 10 & 1 & 0 & 0.054744 & 3.034203 & -0.693728 \\
\hline 11 & 1 & 0 & 2.861336 & -0.079362 & 0.276506 \\
\hline 12 & 1 & 0 & 2.172186 & -0.158019 & 1.769466 \\
\hline 13 & 1 & 0 & -2.881943 & 0.150371 & -1.695675 \\
\hline 14 & 1 & 0 & -3.396313 & 0.150555 & -0.200742 \\
\hline 15 & 1 & 0 & 4.753372 & 0.724057 & -0.332141 \\
\hline 16 & 1 & 0 & 4.652575 & -0.808356 & -0.642401 \\
\hline 17 & 1 & 0 & -0.245084 & -3.033688 & -0.763057 \\
\hline 18 & 1 & 0 & -0.737321 & -3.018617 & 0.738540 \\
\hline
\end{tabular}

